\title{
Development of urban areas of the Russian Federation on the Trans-Siberian Railway: town-planning a railroad role in the city of Krasnoyarsk
}

\author{
Evgine Petrosyan, Ekaterina Kilina \\ Department of Urban Design and Planning, Siberian Federal Unversity, Krasnoyasrk, Russia \\ E-mail: petrosyan.evgine@gmail.com,kilina_katerina95@mail.ru
}

\begin{abstract}
A not populated or low-populated territories development due to the railroads construction exerted considerable impact on regional planning of the country. Construction of the Great Siberian way - the Trans-Siberian Railway was one of the significant events of the end of the 19th century. Numerous new settlements and the cities, such as Novosobirsk, Irkutsk, Krasnoyarsk appeared on the map of the country. Krasnoyarsk began to develop violently and grew by $270 \%$ after railroad construction in 1897 - 1911 years. New created structure of resettlement entailed industry development. A lot of the new productions were transported from the central part of the country during the Second World War. Factories were accommodated along the railroad generally. The majority of objects of cultural railway heritage remained on the railroads territories in present time. The pioneer settlement of railroad workers in the city of Krasnoyarsk - is the Nikolaevskaya sloboda escaped. Typically Siberian residential buildings and style life still characteristic for that unique area. The strategies of the renovation of Nikolaevskaya sloboda area oriented toward the tourist quarter of the Siberian city is required. Development of the city continues. Krasnoyarsk, thanks to the railroad, became the million plus city. Light rail transport, rewatching municipal warehouse territories under cultural clusters, business and residential districts is supposed in the future. Development process is oriented to transformation of the transport oriented district (TOD).
\end{abstract}

Keywords: Trans-Siberian Railway, railroad, Krasnoyarsk, transport oriented district (TOD), Nikolaevskaya sloboda.

\section{Introduction}

The railroad is one of the main transport arteries in Russia. More than $40 \%$ of a passenger turnover and $80 \%$ of all goods turnover of the state are the share of it. Value of railway transport in Russia is fundamental because the country differs in long distances. The level of development of the economy of the state depends on effective work on this system.

Development of a network of the railroads has begun since 1837 . The ceremonial opening of the Russia's first railroad from St. Petersburg to Pavlovsk was held on November 11, 1837. The road St. Petersburg - Moscow became the first most significant railroad construction. Its operation began in 1851.

Railway infrastructure gave a strong impetus for the development of the cities and regions of the country owing to historical tendencies and geographical features. Relevance of studying of a railway system is defined by need of further development of problems of its social and economic development. The railroads continue to play a key role in transport service of the Russian economy, strengthening of integration processes, and also development of urban areas throughout all intervals of the existence.

This type of transport has demanded big capital investments since the first construction 
of the railroad in Russia. But, despite it, the railroad has a number of advantages:

1. Functions round the clock under any weather conditions;

2. Has the low cost of transportations (especially when transporting on long distances);

3. Connects all areas and the regions of Russia;

4. Has the lowest coefficient of impact on the environment.

The objective of this research is the proof that the railroad can function on success and the comfortable environment of the city. The following tasks, proceeding for the purpose were made:

2. To analyze the structure of the railroad in a system of agglomeration of Krasnoyarsk. To reveal that usefulness to the city is at short distances. What communications are necessary.

3. To analyze a historical component of the railroad. To reveal the most significant objects of railway heritage. To track the growth of the city since construction of the railroad.

4. To reveal how the environment of the city and the railroad interact? To offer the development strategy and the technique.

5. To analyze the prerequisites of formation of the transport focused areas along the railroad, to offer the classification and strategy.

Not populated or low-populated territory development due to the railroad construction exerted a considerable impact on regional planning of the country.

History of the Krasnoyarsk railroad is inseparably linked with the history of the city and Krasnoyarsk Krai. The rapid development of the city began with the emergence of the Trans-Siberian Railway more than a century ago. Krasnoyarsk quickly turned into the industrial, scientific and administrative center.

The railway line was transformed to a structural and planning axis around which new urban development was intensively formed. The new urban area is the Nikolaevskaya Sloboda in connection with the inflow of the population occupied on construction of the railroad, service of the railway transport working in railway workshops was formed.

Today scales of the Krasnoyarsk railroad and its importance for Krasnoyarsk Krai give to the highway the status of one of the most important participants of social and economic life of the territory. The operational length of a way of the Krasnoyarsk railroad made $3157,9 \mathrm{~km}$. In 2012. The Krasnoyarsk railroad, transports by trains of the distant and suburban message about 9 million passengers on average in a year.

The Trans-Siberian Railway occupies one of the leading places in the economic infrastructure of Krasnoyarsk area. About 80\% of freights and passengers of the Krasnoyarsk railroad by rail are on average transported. Krasnoyarsk, thanks to the railroad, became the million plus cities.

The railroad penetrates practically all cities. More than 50\% (About 156,6 hectares.) the spaces of the territory of the city are occupied by the railroad tracks and repair and warehouse territories of the railroad. The railway line has very branched structure, and seriously influences coherence and the division of districts of the city. Also, it creates a set of problems in urban areas through which it passes. It is noise pollution, irrational use of valuable lands, formation of marginal territories, a rupture in city fabric.

Modernization of intercity railway transport is supposed in the future. Rewashing railroad municipal and warehouse territories is also necessary under cultural clusters, business and residential districts. Development is directed to the transformation of the transport focused areas in nodal crossings. The areas (TOD) focused on railway transit will unite housing, commercial development, culture and a social assistance. These areas will become available to the pedestrian with qualitative public transport.

\section{Methodology}

Methods of scientific research:

1. Research of international theoretical and practical experience;

2. Studying of scientific literature;

3. Acquaintance with archival documents;

4. Analysis of town-planning documentation and design materials;

5. Natural inspections; 


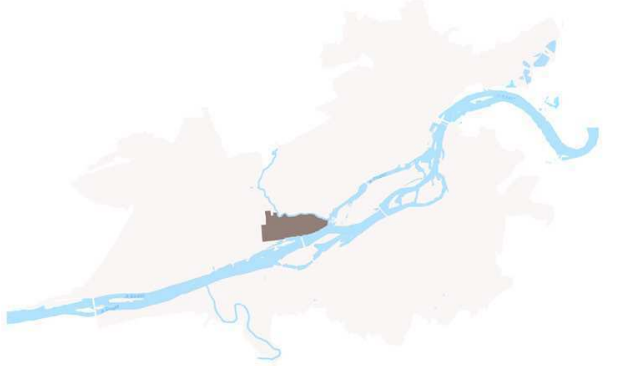

The scheme of the general plan in 1855

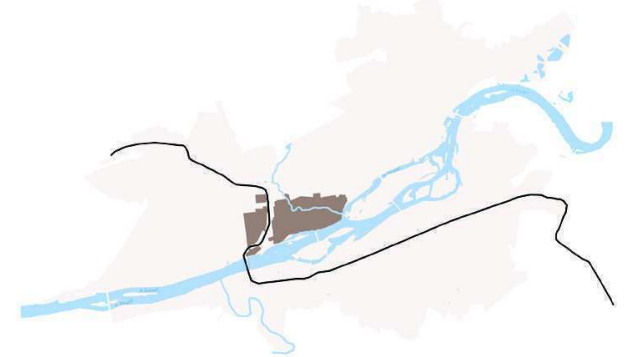

The scheme of the general plan in 1927

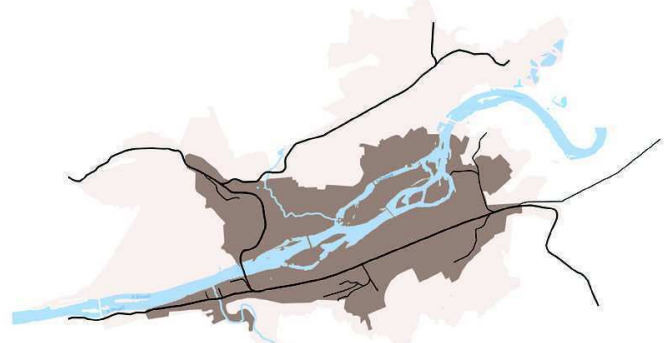

The scheme of the general plan in 1978

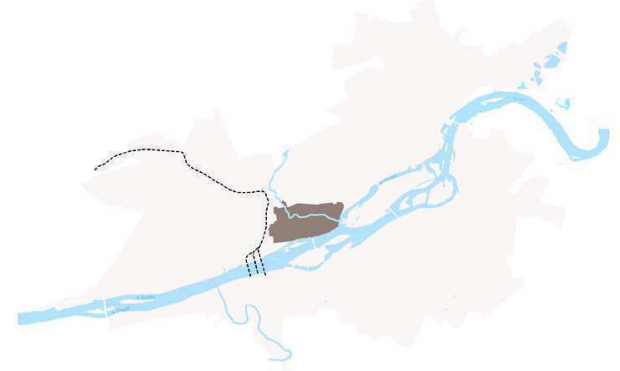

The scheme of the general plan in 1894

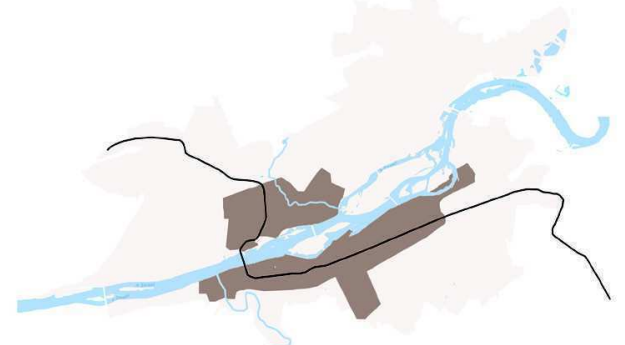

The scheme of the general plan in 1957

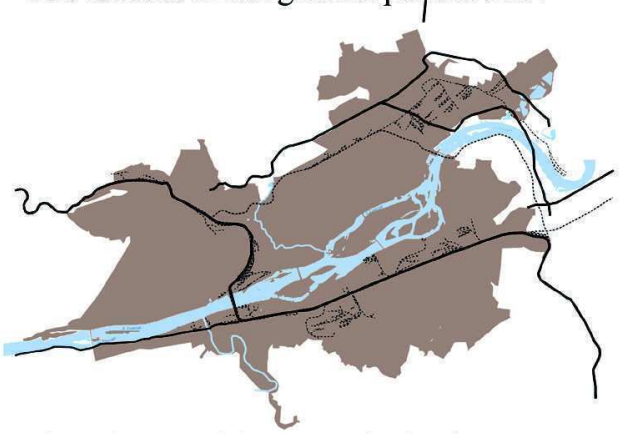

The scheme of the general plan in 2017

Figure 1.

The growth of the city of Krasnoyarsk after the construction of the railway

6. Social poll;

7. SWOT - the analysis.

Three techniques were formulated as a result of the carried-out analysis. They are aimed at the development of historical and cultural potential, formation of the environment and development of the transport focused areas along the railroad.

1. Classification of the railway transport hubs forming the transport focused areas.

Classification of transport and additive knots is offered on the basis of the analysis of territories of the railroad:

1) Transport hubs of city value

2) The formed transport hubs of city value

3) Transport hubs of regional value

4) Transport hubs of trans federal importance
The focused areas which are formed transport have various potential and ways of development depending on category of transport hubs. Objects of different degree of value are formed in these areas.

2. Three approaches to transformation of historically significant territories at railway transport hubs.

Three basic approaches to transformation of territories, according to this technique are offered. It is possible to apply them in certain functional and planning zones:

1) Zone of preservation of valuable historical building.

2) Zone of preservation of morphology of building and structure of land use.

3) Zone of formation of new planning structure of land use. 
The described method of identification of zones with various town-planning, landscape and cultural and historical characteristics and applications to them approaches to renovation, various on extent of intervention, allows to reach a considerable architectural variety, to keep a cultural landscape, important for city history, to receive higher quality of the environment in general.

3. The principles of transformation of historically developed environment Nikolaevskaya sloboda in the transport focused area.

The principles of transformation of the environment were formulated, leaning on the revealed three campaigns of transformation of the territory:

1. Identification and preservation of the objects having historical and cultural value.

2. Preservation of structure of land use.

3. Maximum preservation of low building (introduction of various types of the housing estate).

4. Integration of the designed territory into transport and pedestrian structure of the city.

5. Integration of the designed territory into system of gardening and a recreation of the city.

6. Increase in cultural and historical and tourist capacity of the Nikolaevskaya sloboda.

\section{Measurement and analysis.}

Analysis of railway transport hubs of the city of Krasnoyarsk.

Construction of the Great Siberian Way the Trans-Siberian Railway was one of the significant events of the end of the 19th century. Numerous new settlements and the cities, such as Novosibirsk, Irkutsk, Krasnoyarsk appeared on the map of the country. Krasnoyarsk began to develop violently and grew by $270 \%$ after railroad construction in 1897 - 1911 years (Figure 1).

Carrying out through Krasnoyarsk of the Trans-Siberian railroad influenced city economy. In February, 1891 the final decision on construction of the Great Siberian way was made. The total cost of the road was determined approximately at 350 million rubles. The first train came to the city in 1895 , and in 1899 the railway bridge through the river Yenisei was open. Railway depots and the main railway workshops with carriage, assembly, forge; electromechanical turning shops at that time begin to work in the city. Placement of such enterprises turned the city into the most important industrial center of Siberia. Krasnoyarsk became the central point of the Average-Siberian railroad.

Projects of a bath, cinema, foundry workshop, the pump station of a city water supply system and a large number of houses for a building of the Nikolaevskaya Sloboda in the 1900th - the 1910th years, according to archival data were made. Today the majority of objects of cultural railway heritage, individual Siberian building and the life of Siberians remains.

It was supposed to carry out reconstruction in design developments of the 1920th the 1930th years. Wooden building of the settlement was outlined to demolition. The tendency to preservation of individual building in the Nikolaevskaya Sloboda which kept before the beginning of the 21 st century, in town-planning projects in Krasnoyarsk of the 1950th years was traced.

The Nikolaevskaya Sloboda is the area with the developed individual and expressive architectural and historical environment. It is not presented properly in the modern city. Architectural and cultural and historical value of the area is underestimated in the formation of Krasnoyarsk of the 21st century.

Ten knots were revealed in structure of the city of Krasnoyarsk according to classification of transport and additive knots. It is three knots of city value (the station the overpass, the station railway hospital, the station student's), two formed knot of city value (the station the northern highway, the Krasnoyarsk-northern station), four transport hubs of regional value (the Yenisei station, Zlobino's station, the station Bugach, Bazaikh's station) and one knot of transfederal importance (Krasnoyarskpassenger station) (Figure 2).

We will consider two railway transport hubs and potential of development in more detail. Also, we will consider the formation of the 


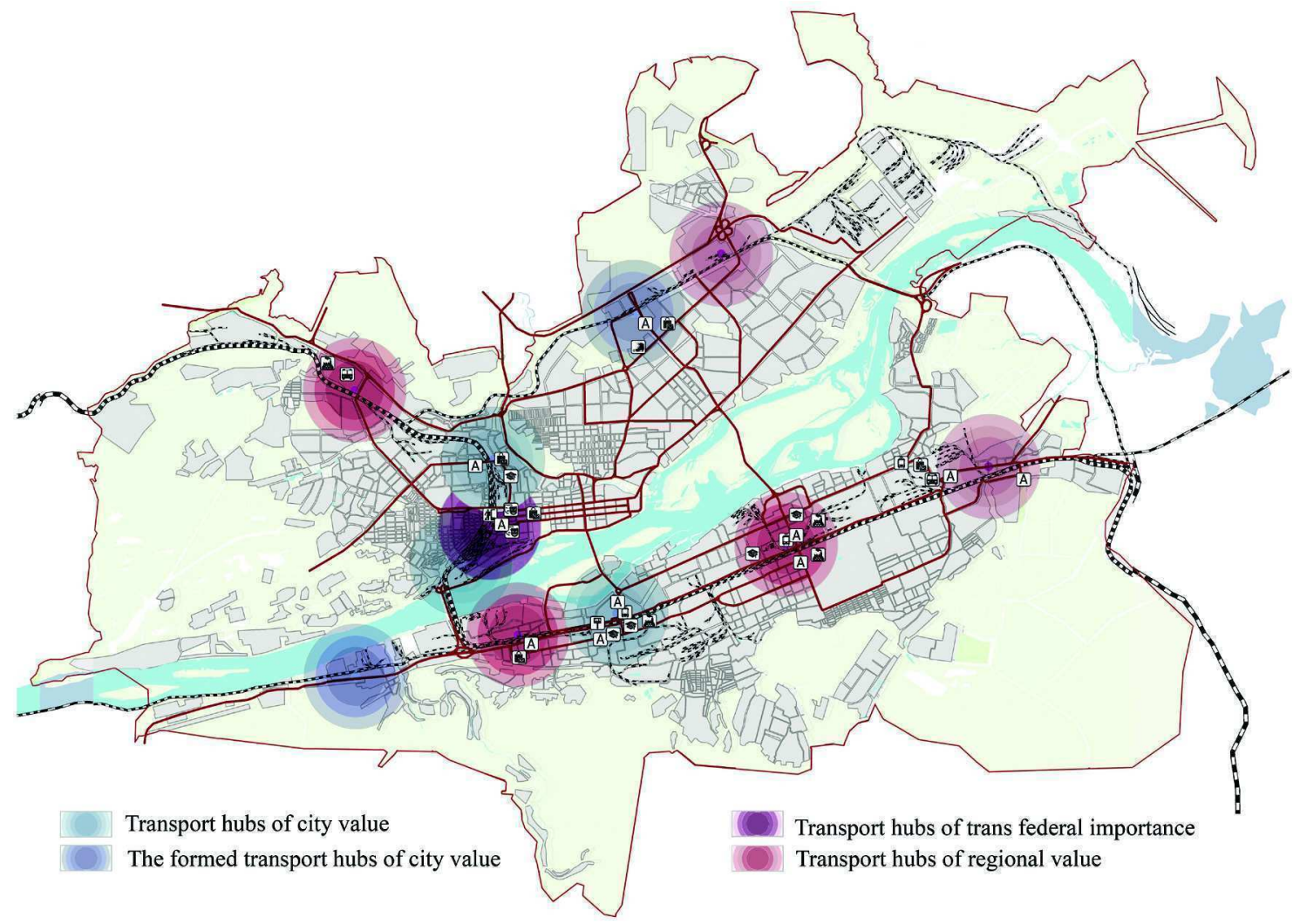

Figure 2.

Classification of the railway transport hubs forming the transport focused areas.

transport focused areas in nearby territories. The first transport hubs of trains federal importance are the Krasnoyarsk-passenger station. The second knot of city value is the station Puteprovod.

\section{Krasnoyarsk-passenger station.}

Historically developed environment settles down near the station. It is the Nikolaevskaya sloboda. The Nikolaevskaya sloboda is the area with the developed individual and expressive architectural and historical environment.

In a result of a conducted natural observation, an analysis of archived documents, trending project materials combined with exploring global theoretical and practical working skills related to a unique homestead building development in an urban area were determined and found "adaptive" progression directions of historical and cultural potentials of Nikolaevskaya Sloboda. The offered "adaptive directions" have become the foundation for the renovation concept of one of the remaining historical areas of Krasnoyarsk. (Figure 3).
1. A zone of preservation of valuable historical building (in figure 3 it is designated in red color). This approach is applied to territories with high concentration of objects which have cultural and historical and architectural value. Transformations in this zone demand careful preservation of historical features of building. Development of the project of zones of protection is necessary. It is with the accurate description of regulations and requirements to reconstruction and new construction. The zone of valuable building forms a historical kernel of the Nikolaevskaya sloboda. It defines its cultural importance for all cities.

2. A zone of preservation of morphology of building and structure of land use (in figure 3 it is designated in orange color). The general nature of individual farmstead building is offered to be kept in this zone without cardinal change of functional purpose of the territory and borders of sites of property. Subjects to building are not subject to protection and obligatory preservation and can be reconstructed or 
1. Zone of preservation of valuable historical building.

2. Zone of preservation of morphology of building and structure of land use.

3. Zone of formation of new planning structure of land use..
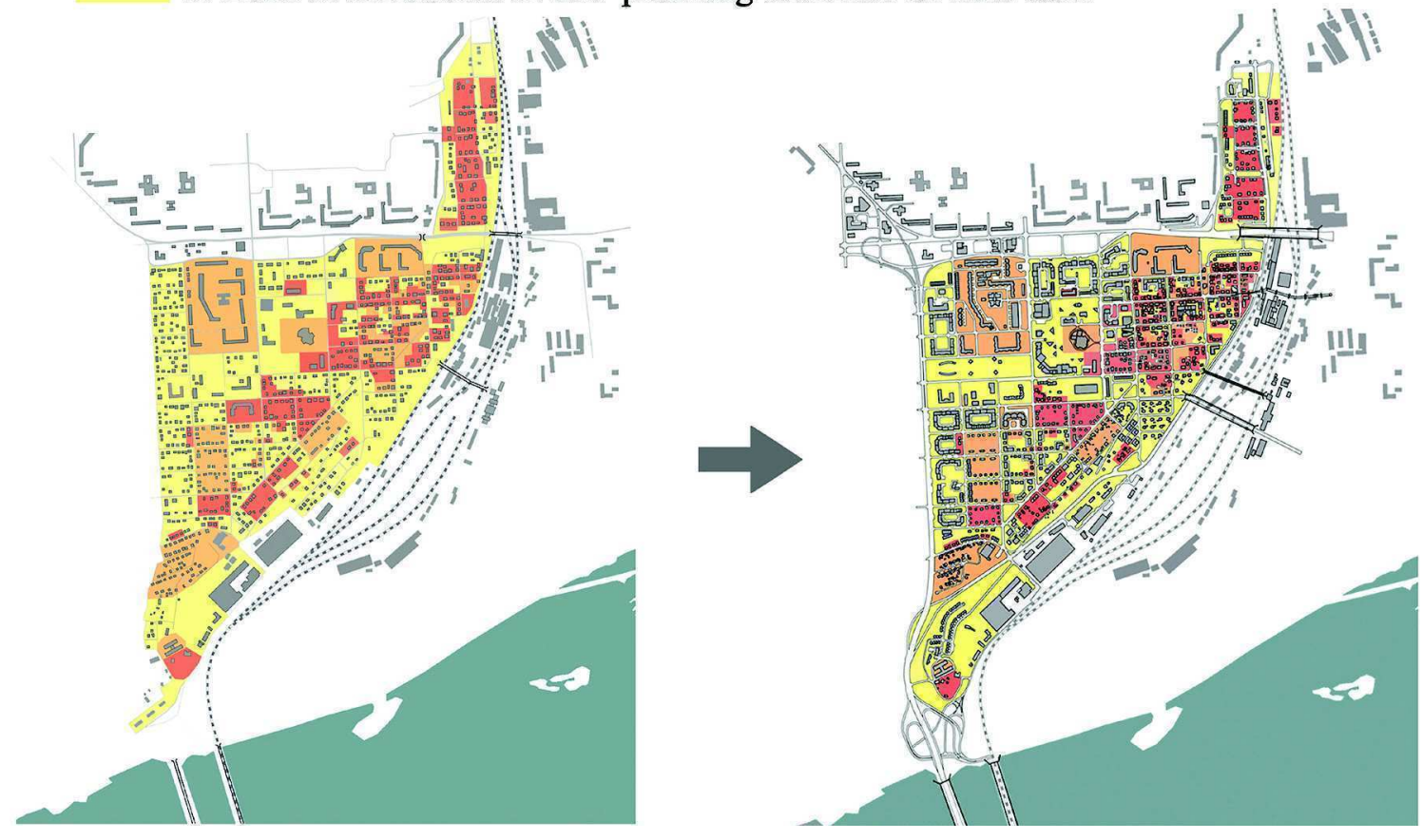

Figure 3.

Three approaches to transformation of historically significant territories at railway transport hubs.

reconstructed within the general parameters of the allowed use (the maximum number of stores, building coefficient). It is focused in this approach on stimulation of locals to independent improvement of the housing conditions. Participation of third-party developers in development of the territory is not excluded on condition of observance of the general requirements to the nature of building.

3. A zone of formation of new planning structure of land use (in figure 3 it is designated in yellow color). Change of typology and (or) functional purpose is supposed on the sites carried to this zone. For example, emergence of the new thoroughfare which connects the new bridge with this area cannot but affect the nature of building of adjacent territories.

The principles of transformation of historically developed environment Nikolaevskaya sloboda in the transport focused area.

Leaning on the revealed three campaigns of transformation of the territory six principles of transformation of the environment were formulated (Figure. 4):
- Identification and preservation of objects which have historical and cultural value. unique architectural and planning features were revealed as a result of careful on-site investigation of houses and public buildings in the Nikolaevskaya sloboda. They allowed disclosing the historical and cultural importance of the area for preservation of an originality of our city. The majority of structures are not entered in the register of monuments of cultural heritage. Objects the architectural details, design features and materials reflect the value of a certain time and the place. They are single copies in historical building of Krasnoyarsk;

- Preservation of structure of land use. The maximum preservation of the developed structure of land use with increase in quantity of the planted trees and shrubs spaces at the expense of territories of the demolished shabby housing is supposed;

- Maximum preservation of low building (introduction of various types of the housing estate). All decisions are directed to the maximum preservation of low building of the Nikolaevskaya sloboda as unique planning area. 


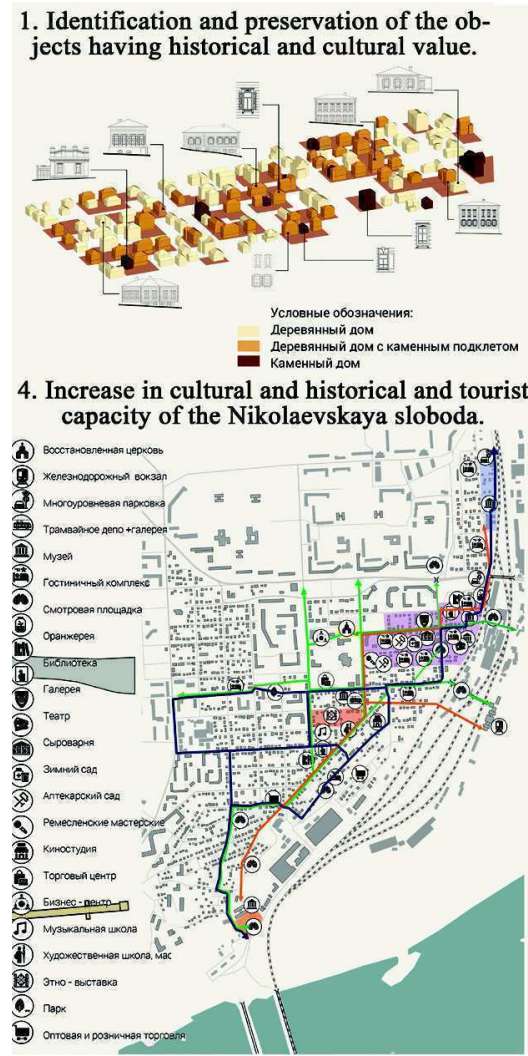

The principles of transformation of historically developed environment Nikolaevskaya sloboda in the

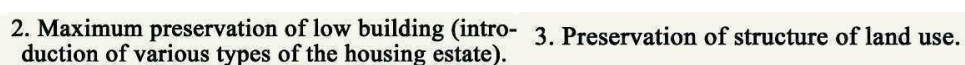
( various types of the housing estate).

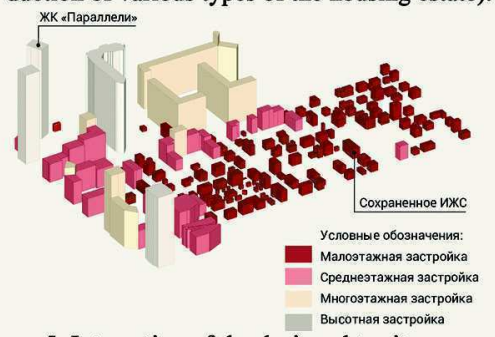

5. Integration of the designed territory into system of gardening and a recreation of the city.

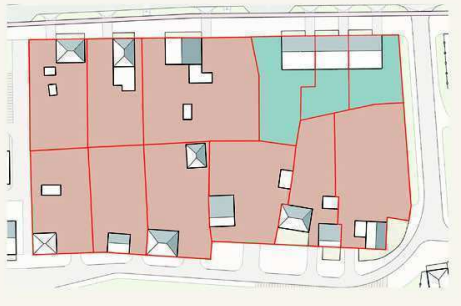

6. Integration of the designed territory into transport and pedestrian structure
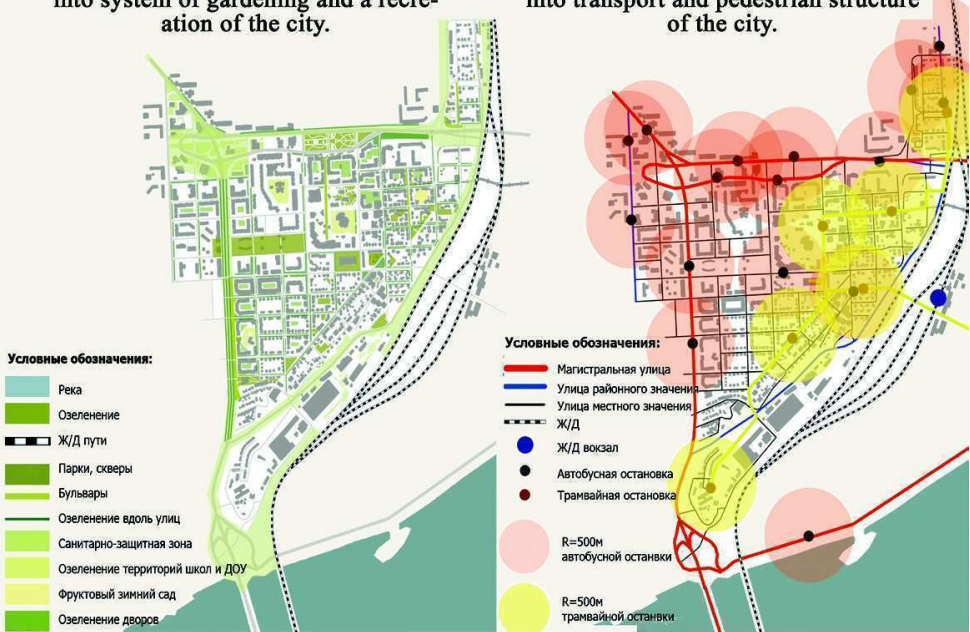

Figure 4 transport focused area.

It emphasizes with the undersized structures a natural landscape of slopes of the Afontovy Mountain. Construction of average number of stores by buildings is planned fragmentary. It is transitional type to the existing multistoried area;

- Integration of the designed territory into transport and pedestrian structure of the city. The concept is executed taking into account the automobile outcomes of the fourth bridge, and also two new outcomes which are already constructed and planned to construction. This principle has to promote integration of the Nikolaevskaya sloboda with other districts of the city. The organization of the convenient pedestrian movement is provided. The majority of streets are transferred to category of pedestrian and transport. The boulevards having an exit to the neighboring residential districts are designed. Strips for cyclists are allocated and streetcar service on streets of the settlement and through the automobile bridge to the downtown is designed;
- Integration of the designed territory into system of gardening and a recreation of the city. The decision assumes systems of the planted trees and shrubs and recreational spaces of the Nikolaevskaya sloboda. It is creation of protective many-tier gardening along thoroughfares, the safe pedestrian movement, and the organization of rest and on integration into the general system of the city is directed to their rather uniform placement on the inhabited territories;

- Increase in cultural and historical and tourist capacity of the Nikolaevskaya sloboda. In the concept solutions on creation of the tourist routes uniting historically significant, key places of the area with building, characteristic of it, are proposed. Installation of small architectural forms, the information installations telling about Place history, the organization of museum platforms is provided. Development of agro tourism is not excluded on the basis of individual farmstead building. All this will make more available studying 
of identity of the Nikolaevskaya sloboda and traditional tenor of life of its inhabitants.

\section{The station Puteprovod.}

The station Puteprovod station is in the central part of the city. Here 3 look city transports - railway (the overpass and the station - the top level), the bus and trolleybus movement, and also individual city transport - the car are crossed. The station is developed. It is with the plentiful pedestrian streams. This place is transit. Around the railroad more than $70 \%$ occupy garages.

This station has a high potential to become multifunctional transfer knot with the transport focused area. The territories around the station are empty, or are occupied with garage cooperative, or absolutely abandoned. In this territory there is not enough accompanying service and existence of a cultural and entertaining and public and business zone.

The urban environment around the station is friable, there is no clear boundary. The pedestrian space along the railroad is unorganized. Transport entrances are inconvenient to the next residential buildings. Shortage of social institutions of the next areas, domestic spaces is felt. Children play in the middle of the railroad; there is no all making safety along the railroad.

During the research, borders of the transport focused area and extent of influence of transport hubs on the area were defined. In the center of the transit focused area the railway station is located. The center is surrounded with rather dense building. In the course of removal from density of the center construction decreases. The transit focused building settles down at distance ranging from 400 to 800 meters from transit stations and stops. It settles down in a zone of pedestrian availability (Figure 5).

After the analysis and delimitation the concept of renovation and strategic development of the territory of the transport focused area was offered.

Such strategic planning is necessary for formation of conditions of sustainable social and economic development of urban railroad areas, increase of mobility of the population

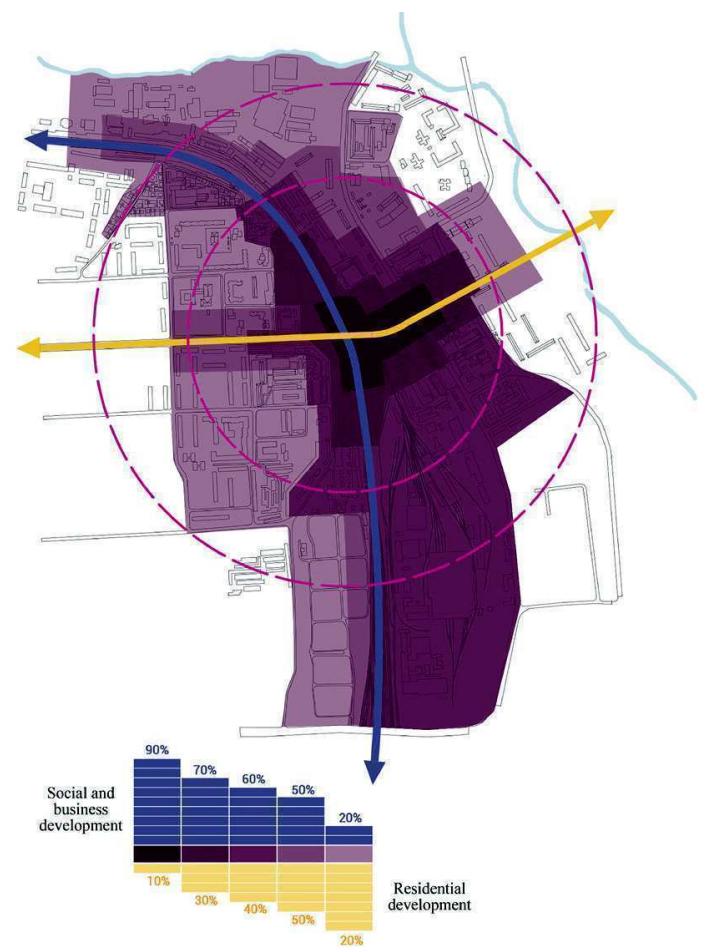

Figure 5.

Borders of the transport focused area and extent of influence of transport hubs on the area

and optimization of pedestrian and traffic flows, and also innovative development of the railway transport which is harmoniously coordinated to development of other means of transport.

Strategy is directed to the solution of the following tasks:

- Formation of available and steady transport system as infrastructure basis for ensuring transport integrity, independence, safety of the area,

- Social and economic growth and providing conditions for realization of needs of the population for transportations;

- Realization of city transit potential on the basis of integration of railway transport into transport system of the city;

- Creation of conditions for deepening of economic integration and increase in mobility of a manpower;

- Decrease in cumulative transport expenses, including due to increase in efficiency of functioning of railway transport;

- Increase in investment appeal of railroad territories;

- Creation of comfortable and favorable, 


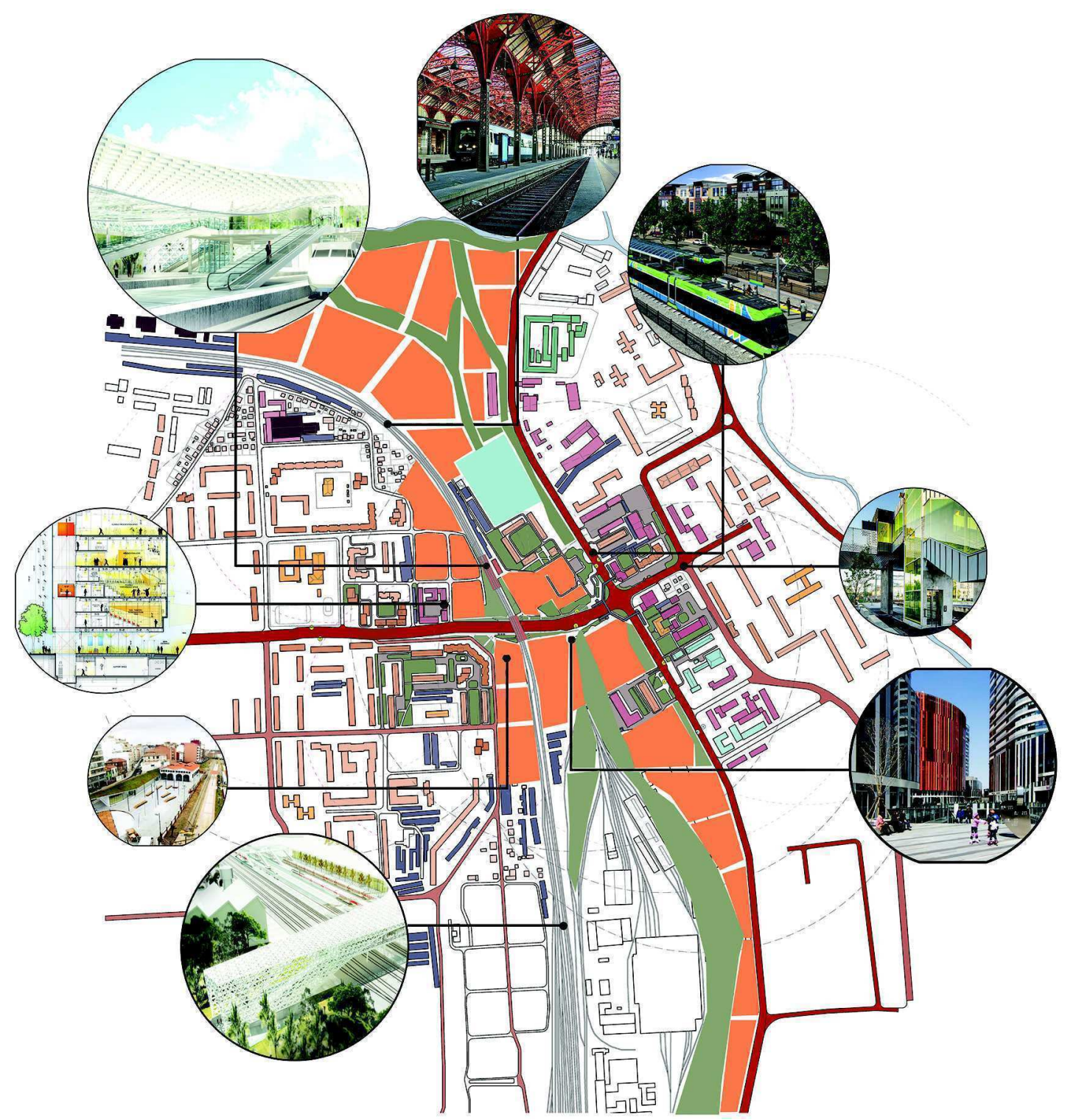

Figure 6.

Schema concept of renovation and strategic development of the territory of the transport focused area

ecologically safe environment of the transport focused area;

The territory can become the region of a multipurpose orientation. It is: the railway station serving trains of city, regional, and also regional value. Placement of business center, office, commercial and hotel, sports and recreational zones is supposed. The educational function extends. The territory of the existing technical school increases, construction of new cases is planned. The high comprehensive school will be orientated, and also the new school of 2000 thousand children is added.
Construction is planned different typology of the housing estate: multistoried quarter type, high-rise, social housing for young families and students, apartments, housing of hotel type, and also individual housing, townhouses, city country houses.

The area in strategy is integrated into system of a city transport-pedestrian framework. It has six stopping points of public land transport, and also four stations of easily rail transport. All stopping points are in pedestrian availability, have canopies, are equipped with a warm contour, the device for handicapped national 
groups and connected among themselves by the aboveground, underground and elevated covered crosswalks.

Creation of the system of gardening, including the park zones, squares connected among themselves by a system of boulevards and pedestrian streets is supposed. Reconstruction, the organization and improvement of the river embankment of Kacha is provided. The domestic planted trees and shrubs space at the different levels is designed in quarters. It is the operated "green" roofs.

The main parking zones are designed along the railway tracks intended for use by residents and for public and business appointment. They are land multilevel. They serve as protection for residential quarters against noise. Parking spaces are intended for continuous, temporary and guest storage of cars.

The underground, or entered in a relief parking's are located for the continuous storage of cars of residents in the area. Land guest parking's are provided along commercial institutions.

\section{Conclusion}

Result of a research is the developed technique of planning of the territories located along the railroads and historically significant territories at railway transport hubs, and also the transit focused areas.

The presented three approaches of renovation can be used for transformation and preservation of historical significant environments in the cities of Russia. Such approach is universal. The listed principles of transformation of historically developed environment in the transport focused area can be used in similar areas which basis is sustainable development.

The transport focused development (TOD) allows providing compact and multipurpose development of zones within walking distance of intercity railway transport. We provide the basic principle of TOD. This principle is granting qualitative public transport. Good transport service always attracts people. It reduces dependence on the car and expense both people, and local self-government. TOD can bring benefit to local economy by means of the mixed land use. It increases economic activity due to diversification and availability of goods and services.

We tried to optimize as much as possible all pedestrian and traffic flows, at comfortable and favorable building and urban environment in our strategy of development for the transport focused areas at transfer knots of various category.

We proved that the railroad can function on success and the comfortable environment of the city while fast growth causes a number of problems for the cities. Our urbanized approach gives an opportunity to change city planning. It promotes its harmonious development and the organization of districts of the city with the increased density of population.

\section{References}

Petrosyan, E. and Kilina E. (2017) 'The concept of renovation of Nikolaevskaya sloboda in the city of Krasnoyarsk, Construction formation lifetime activities unpublished Conference proceedings.

Chernyshov V. (2011) In 1628 the city of Krasnoyarsk was founded. (http://www. krasplace.ru/sloboda-nikolaevka) accessed 7 August 2011.

Importance of railway transport. The main indicators of the work of the railways. (http://www.modelzd.ru/ustroystvo-zhd/ znachenie-zhd-transporta.html) accessed 11 November 2014.

Tereshkova. M. (2011) Sloboda Nikolaevka (http://www.krasplace.ru/slobodanikolaevka) accessed 7 April 2011.

Veronika A. (2014) Rails from the past. How the railways raised Russia. (https://www. gazeta.ru/business/2014/11/10/6296941. shtml) accessed 11 November 2014. 